\title{
Saturação por bases na integração lavoura-pecuária com cultivo de milho nos dois primeiros anos
}

\author{
Arismar Ribeiro Brito ${ }^{1}$, Henildo de Sousa Pereira ${ }^{2}$, Elizeu Luiz Brachtvogel ${ }^{1}$ \\ Instituto Federal de Educação, Ciência e Tecnologia de Mato Grosso - IFMT, Confresa, MT. Universidade Estadual de \\ Mato Grosso -UNEMAT, Alta Floresta, MT. E-mail: enildop@gmail.com
}

\section{RESUMO}

A maioria das pastagens no Cerrado encontra-se com algum grau de degradação. A estratégia de introduzir a cultura do milho em consórcio com capim na recuperação das pastagens é uma alternativa viável. Mas como os solos do Cerrado são ácidos, para que essa técnica seja viável, dentre tantos outros fatores, um dos principais é conhecer qual o nível de saturação por bases para o milho em consórcio. Assim, o presente estudo objetivou avaliar o efeito de níveis de saturação por bases sobre o crescimento e a produção da cultura do milho, consorciado ou não com Urochloa brizantha cv. Marandu nos dois primeiros anos após a correção. O delineamento experimental foi o de blocos ao acaso, com quatro repetições, dispostos em esquema fatorial $4 \times 2$, sendo: quatro níveis de saturação por bases do solo (25\% "controle: sem calcário", 45, 60 e 75\%) e duas modalidades de cultivo (Milho+Marandu "consorciado" e Milho "monocultura"), sendo o capim semeado 25 dias após a semeadura do milho e na entre linha. No primeiro ano de avaliação não houve diferença para nenhum dos fatores testados, isso ocorreu pelo fato de não ter havido tempo para uma adequada reação do calcário entre a aplicação e cultivo do milho. No segundo ano, as formas de cultivo também não diferiram, já os níveis de saturação influenciaram a cultura do milho. No cultivo consorciado, os níveis de saturação por bases próximas de 56 e 53\%, apresentaram maiores valores para altura de planta e altura de inserção de espiga, respectivamente. A produtividade do milho em monocultivo foi maior na saturação por base aproximadamente $47 \%$, já para o milho+Marandu a máxima produtividade foi obtida na saturação próxima a $65 \%$. O consórcio com capim Marandu não interferiu na produtividade do milho. As saturações por bases que resultaram em maiores produtividades foram próximas de 50 e $65 \%$ para o cultivo milho+Marandu e monocultivo, respectivamente.

Palavras-chave: braquiária; correção da acidez do solo; recuperação de pastagens; Zea mays L.

\section{Effect of levels of base saturation on corn culture in the first two years in integration crop-livestock}

\begin{abstract}
Most pastures in the Cerrado have some degree of degradation. The strategy of introducing maize in a intercropping with grass in pasture recovery is a viable alternative. But because the Cerrado soils are acidic, for this technique to be feasible, among other factors, one of the main factors is to know the level of base saturation for corn in a intercropping. The objective of this study was to evaluate the effect of base saturation levels on corn crop growth and yield, intercropped or not with Urochloa brizantha cv. Marandu in the first two years after the correction. The experimental design was randomized complete block design with four replicates, arranged in a $4 \times 2$ factorial scheme, with four levels of base saturation ( $25 \%$ "control: no lime", 45, 60 and 75\%) and two forms of cultivation (corn+Marandu "intercropped" and corn "monoculture"), with the grass sown 25 days after maize sowing and in line. In the first year of evaluation, there was no difference for any of the factors tested, this was due to the for missed time. In the second year, the cultivation forms did not differ as well, saturation levels influenced the corn crop. In the intercropping the base saturation levels of $56 \%$ and $53 \%$ presented higher values for plant height and spike insertion height, respectively. The yield of corn in single crop was higher in saturation by baseline by approximately $47 \%$, while for the intercropped, the maximum yield was obtained at saturation $65 \%$. The Marandu grass intercropped did not interfere with corn productivity. Corn did not respond to the
\end{abstract}


application of lime in the same year of cultivation. The base saturations that resulted in higher yields were close to 50 and $65 \%$ for solecropped and intercropped cultivars, respectively.

Keywords: brachiaria; correcting of soil acidity; recovery of degraded pasture; Zea mays L.

\section{Introdução}

Em países com a pecuária em desenvolvimento (grupo no qual o Brasil está inserido), a implantação e condução de sistemas de produção que maximizam a produtividade, estão cada vez mais em evidência, pois um sistema que aumenta e diversifica a produtividade, consequentemente reduz os impactos ambientais. Assim, um sistema de produção que além de produzir grãos, ainda produz a forragem para alimentação de animais requer atenção em Regiões de destaque na criação de bovinos.

O Brasil detém o maior rebanho bovino do mundo, cerca de 222 milhões de animais em 2017 (ABIEC, 2018), ocupando uma área de aproximadamente 159 milhões de hectares (45\% da área destinada a produção agropecuária) (IBGE, 2017). Desse total, o estado do Mato Grosso contribui com (14\%), aproximadamente 31 milhões de animais (ABIEC, 2018), sendo o maior produtor.

Embora tenha o maior rebanho bovino do mundo, a pecuária brasileira apresenta baixa eficiência de produtividade (LOPES; NETO, 2011). Isso é reflexo da degradação das pastagens, onde aproximadamente $80 \%$ apresentam algum grau de degradação (DIAS-FILHO, 2014). No Estado do Mato Grosso, a maior parte das áreas ocupadas por pastagens também se encontram com algum grau de degradação, sendo necessário a recuperação/ou renovação. No entanto, os métodos tradicionais de recuperação de pastagens são muito onerosos, em especial pela necessidade de correção e fertilização (CRUSCIOL et al., 2011), fazendo-se necessário a utilização de outros métodos.

A estratégia de recuperação/ou renovação de pastagem conjuntamente com o consórcio de culturas de grãos tem se mostrado uma alternativa viável (ALVARENGA et al., 2008; CARVALHO et al., 2017), sendo uma das estratégias mais promissoras para desenvolver sistemas de produção menos intensivos no uso de insumos e, por sua vez, mais sustentáveis no tempo (MACEDO, 2009).

No sistema "Santa Fé", um dos mais difundidos de integração lavoura-pecuária, utiliza-se o consórcio de cereais com forrageiras do gênero Urochloa sp.. Nesse caso, a cultura do milho surge como uma alternativa viável, pelas diversas aplicações deste cereal dentro da propriedade agrícola (TROGELLO et al., 2012). Assim, avaliar a cultura do milho em sistemas onde além de ter a produtividade da cultura ainda tem a renovação da pastagem é de extrema importância, pois é uma alternativa para os produtores que, na maioria das vezes, não renovam as áreas pelo elevado custo (GONTIJO NETO et al., 2018).

Como a maior produção de bovinos no Brasil se dá em áreas naturalmente de baixa fertilidade, ou que estão sob muitos anos de exploração sem o manejo adequado, sem correção e adubação, esse custo fica ainda mais elevado. Diante disso, estratégias para recuperar essas áreas com a diluição de custos são fundamentais para se buscar uma exploração econômica, social e sustentável, reduzindo os danos ao meio ambiente (DIAS-FILHO, 2017).

Já é conhecido que a maioria dos solos brasileiros são ácidos afetando, assim, a disponibilidade de vários nutrientes para as plantas, prejudicando seriamente os rendimentos da maioria das culturas (FAGERIA, 2001). Desse modo, a calagem é uma prática necessária para corrigir acidez e fornecer $\mathrm{Ca}^{2+}$ e $\mathrm{Mg}^{2+}$ na maior parte dos solos brasileiros, principalmente na região do cerrado, uma vez que estes se caracterizam como ácidos.

A recomendação de calagem pode ser realizada por diversas formas, de acordo com a região, sendo o método de saturação por bases o indicado para solos da região Centro Oeste (SOUSA et al., 2007). Na Região Nordeste de Mato Grosso, não tem trabalhos com saturação por bases para a cultura do milho, quando esta é cultivada em consórcio com forrageiras o que torna fundamental pesquisas nesta área.

Alguns trabalhos verificaram o maior requerimento em fertilidade do solo devido a interferência do cultivo de forrageiras em consórcio com o milho (FONSECA et al., 2011), uma vez que em áreas cultivadas simultaneamente pode haver maior exigência de nutrientes em relação ao seu cultivo solteiro, 
devido a competição das forrageiras por água, luz e nutrientes (DUARTE et al., 2013). Por outro lado, Tsujigushi et al. (2013) não encontraram diferença quanto a dose de calcário na produtividade de milho em consorcio com Urochloa ruziziensis. Dessa forma, são fundamentais trabalhos que buscam avaliar a correção da acidez do solo em cultivo milho+Marandu e monocultivo.

Assim, o presente estudo objetivou avaliar o efeito de níveis de saturação por bases sobre o crescimento e produtividade da cultura do milho em monocultivo e milho+Marandu nos dois primeiros anos após a correção do solo.

\section{Material e Métodos}

Conduziu-se um experimento durante dois anos consecutivos (safra 2010/11 e 2011/12) no Instituto Federal de Mato Grosso (IFMT) Câmpus Confresa, localizado nas coordenadas geográficas $10^{\circ} 39^{\prime} 40^{\prime \prime} \mathrm{S}$ e $51^{\circ} 33^{\prime} 11^{\prime \prime} \mathrm{W}$, com altitude de aproximadamente $230 \mathrm{~m}$, solo classificado como Latossolo Amarelo Distrófico. O clima da região é, segundo a classificação de Köppen, do tipo Aw, tropical com estação seca de inverno (junho a agosto) e verão chuvoso (dezembro a fevereiro), os dados de precipitação e temperatura do período de condução do experimento estão na Figura 1.

Figura 1. Precipitação pluviométrica e temperaturas máxima, média e mínima diária, nos anos de condução do experimento. Confresa - MT. Fonte: Instituto Nacional de Meteorologia -INMET, 2013.

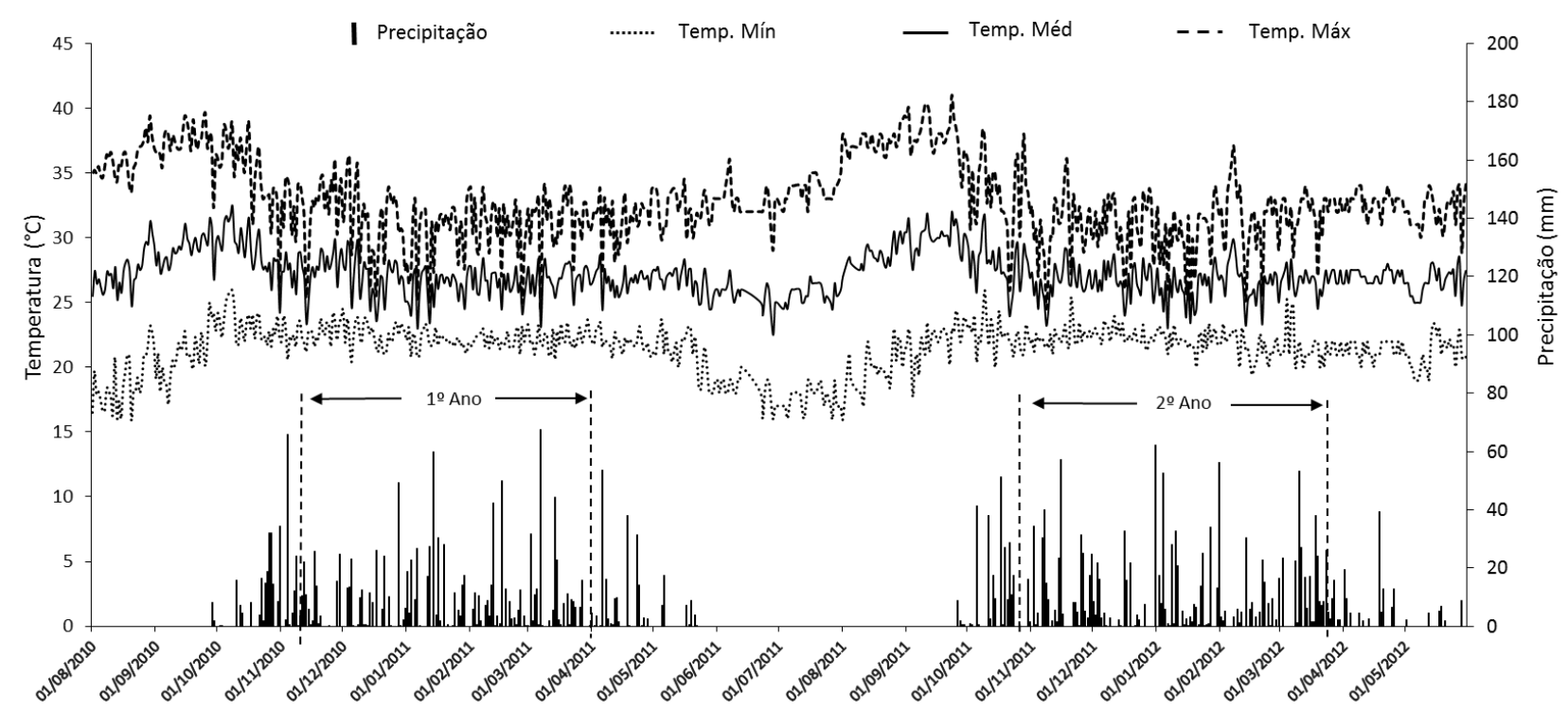

Período Experimental

Anteriormente à instalação do experimento, foi realizada a coleta de solo na camada de 0,00 - 0,20 m para análise química conforme metodologia descrita por Raij et al. (2001), apresentando as seguintes características químicas: $\mathrm{pH}$ em $\left(\mathrm{CaCl}_{2}\right)=4,4 ; \mathrm{Al}^{+3}=0,2 \mathrm{cmol}_{\mathrm{c}} \mathrm{dm}^{-3}$ $; \mathrm{H}+\mathrm{Al}=3,9 \mathrm{cmol}_{\mathrm{c}} \mathrm{dm}^{-3} ; \mathrm{MO}=22 \mathrm{~g} \mathrm{~kg}^{-1} ; \mathrm{Ca}^{2+}=0,7$ $\mathrm{cmol}_{\mathrm{c}} \mathrm{dm}^{-3} ; \mathrm{Mg}^{2+}=0,2 \mathrm{cmol}_{\mathrm{c}} \mathrm{dm}^{-3} ; \mathrm{P}=3,5 \mathrm{mg} \mathrm{dm}^{-3}$ (resina); $\mathrm{K}^{+}=0,41 \mathrm{cmol}_{\mathrm{c}} \mathrm{dm}^{-3} ; \mathrm{CTC}=5,21 \mathrm{cmol}_{\mathrm{c}} \mathrm{dm}^{-}$ 3 , saturação por bases $\mathrm{V} \%=25$, Al saturado $=$ $13 \%$, e argila $=23 \%$, silte $=7 \%$ e areia $=70 \%$, e de acordo com os valores descritos na análise foram realizado as recomendações de calagem (zero; 1,17; 2,05 e 2,94 Mg ha ${ }^{-1}$ de acordo com cada tratamento), a adubação foi realizada de forma semelhante para todas as parcelas, sendo: no plantio (400 $\mathrm{kg} \mathrm{ha}^{-1}$ do adubo 4-14-8 na linha de plantio) e na cobertura em estádio V5 (80 $\mathrm{kg} \mathrm{ha}^{-1}$ de $\mathrm{N}$ na forma de ureia e $20 \mathrm{~kg} \mathrm{ha}^{-1}$ de $\mathrm{K}_{2} \mathrm{O}$ na forma de $\mathrm{KCl}$, localizado ao lado da linha de plantio) seguindo a recomendação proposta por (RAIJ et al., 1997). Os tratos culturais foram realizados sempre que necessário, onde o controle das plantas daninhas foi feito através de capina manual, e o controle de inseto praga e doenças com defensivos agrícolas.

O delineamento experimental adotado foi o de blocos ao acaso, com quatro repetições. Sendo os tratamentos dispostos em arranjos fatorial $4 \times 2$, constituídos da combinação de quatro níveis de saturação por bases: $25 \%$ "sem correção"; 45(1,17); 60(2,05) e 75\%(2,94) valor entre parênteses corresponde a dose aplicada em $\mathrm{Mg} \mathrm{ha}{ }^{-1}$ e duas modalidades de cultivo (milho 
com Brachiaria na entre linha de semeadura e monocultura de milho), testados em parcelas de $5 \times 8 \mathrm{~m}\left(40 \mathrm{~m}^{2}\right)$, com área útil de $16,2 \mathrm{~m}^{2}$ (três linhas centrais de $6,0 \mathrm{~m}$ ).

No início da safra 2010/11 foi instalado o experimento, aplicando a lanço de forma manual o calcário dolomítico (PRNT de 88\%) no início do período chuvoso $(25 / 09 / 10)$ e incorporado na camada de 0,0-0,2 m utilizando grade aradora e posteriormente nivelado, em 14 de novembro de 2010 foi realizada a semeadura do híbrido de milho AG 1051, espaçados em 0,9 m entre linhas e a população de 50 mil plantas ha ${ }^{-1}, 25$ dias após, o capim Marandu foi semeado na entre linha do milho, utilizando 350 pontos de valor cultural ha ${ }^{-1}$. Essa estratégia de semeadura entre o milho e o capim foi utilizada para reduzir a interferência da forrageira na cultura do milho e também para não comprometer o estabelecimento do capim.

Para o início da segunda safra (2011/12), o capim Marandu da safra anterior foi dessecado em 23/09/2011 utilizando glyphosate $(2,16 \mathrm{~kg}$ e. a. ha $\left.{ }^{-1}\right)$, e após secar foi roçado e os restos culturais mantidos nas parcelas. O plantio seguiu a mesma recomendação do primeiro ano. A adubação e os tratos culturais foram semelhantes em todas as parcelas nos dois anos de condução do experimento, bem como o híbrido de milho e cultivar da forrageira foi a mesma para os dois anos. Para avaliação do desenvolvimento da cultura do milho, foram avaliadas as seguintes características: altura de plantas (AP), que corresponde à distância entre a superfície do solo e a folha bandeira; altura de inserção de espiga (AIE) que corresponde à distância entre a superfície do solo e a base da inflorescência feminina; relação entre altura da espiga e altura da planta (AE/AP), foi obtida pela razão entre AIE e AP; diâmetro do colmo (DC) do primeiro entrenó acima do colo da planta, essas medidas foram feitas de forma aleatória em 10 plantas da área útil da parcela, quando as plantas estavam em florescimento pleno. Massa de mil grãos $(1000 \mathrm{G})$, foi determinada segundo metodologia descrita na RAS (BRASIL, 2009), e o teor de água dos grãos corrigido para $13 \%$ e produtividade de grãos (PG) em Kg ha ${ }^{-1}$ foi obtida a partir da colheita e pesagem de grãos provenientes das espigas da área útil de cada parcela, corrigido para $13 \%$ de umidade.

Os dados foram submetidos à análise de variância pelo teste $F$ utilizando o software Sisvar (FERREIRA, 2011). Quando constatada significância foi realizado o teste de média para formas de cultivo, e análise de regressão para os níveis de saturação por bases, calculada para equações de primeiro e segundo graus, quando ambas as equações apresentaram significância, optou-se por aquela com maior coeficiente de determinação $\left(R^{2}\right)$. Em caso de interação procedeu-se com o desdobramento.

\section{Resultados e Discussão}

Os valores de $\mathrm{F}$ calculado para as fontes de variação dos fatores isolados, e também da interação, referente ao primeiro ano de cultivo do milho (2010/11), para as características morfológicas, massa de 1000 de grãos e produtividade estão expostas na (Tabela 1).

Tabela 1. Resumo da análise de variância para as variáveis altura de planta- AP (cm), inserção de espiga -AIE $(\mathrm{cm})$, relação AIE/AP, diâmetro do colmo - DC $(\mathrm{mm})$, massa de mil grãos - M1000 (g) e produtividade - PG ( $\mathrm{kg} \mathrm{ha}^{-1}$ ) em área de primeiro ano de cultivo de milho híbrido AG 1051 cultivado na safra 2010/2011 em Confresa-MT, Brasil.

\begin{tabular}{ccccccc}
\hline \multirow{2}{*}{ Fonte de variação } & \multicolumn{7}{c}{ Variável } \\
\cline { 2 - 7 } & AP & AIE & AIE/AP & DC & M1000 & PG \\
\hline Cultivo (C) & $1,046^{\mathrm{NS}}$ & $0,025^{\mathrm{NS}}$ & $1,001^{\mathrm{NS}}$ & $1,361^{\mathrm{NS}}$ & $0,009^{\mathrm{NS}}$ & $0,012^{\mathrm{NS}}$ \\
\hline Saturação(S) & $0,500^{\mathrm{NS}}$ & $2,769^{\mathrm{NS}}$ & $2,848^{\mathrm{NS}}$ & $0,459^{\mathrm{NS}}$ & $0,822^{\mathrm{NS}}$ & $0,962^{\mathrm{NS}}$ \\
\hline C x S & $1,703^{\mathrm{NS}}$ & $1,541^{\mathrm{NS}}$ & $0,186^{\mathrm{NS}}$ & $1,104^{\mathrm{NS}}$ & $0,620^{\mathrm{NS}}$ & $0,964^{\mathrm{NS}}$ \\
\hline Média & 149 & 69 & 0,46 & 13,91 & 249,74 & 3066,11 \\
C.V. (\%) & 15,56 & 8,05 & 8,69 & 4,80 & 8,94 & 20,75 \\
\hline
\end{tabular}

$* *, *$ e NS: significativo $(\mathrm{p}<0,01),(\mathrm{p}$

$<0,05)$ e não siginificativo, respectivamente, pelo teste $F$. 
Observa-se que não houve diferença para os fatores testados isoladamente, tampouco para interação (Tabela 1). Esta não resposta do milho para os níveis de saturação por bases, evidencia que a aplicação de calcário no mesmo ano agrícola não foi efetiva na correção da acidez do solo, visto que o período entre a aplicação do corretivo e o plantio foram de 50 dias, vale ressaltar que aproximadamente 20 dias deste período, o solo esteve sem umidade suficiente para ocorrer a reação do calcário, o que pode ter contribuído para não haver resposta.

O calcário necessita de tempo em condições de umidade e temperatura para reagir, esse tempo pode variar em função da precipitação pluvial, se o tempo em condições de reação for curto, pode não haver resposta como o esperado. Estudando períodos de aplicação de calcário até 75 dias antes da semeadura, Castro et al. (2013a) concluíram que o desenvolvimento do milho foi influenciado pelo tempo de reação do calcário, e enfatizam que quanto maior o tempo de reação do calcário no solo maior o desenvolvimento das plantas. A ação corretiva da acidez do solo ocasionada pelo calcário permanece crescente até os 180 dias após a incubação (CALONEGO et al., 2012). A aplicação de $4 \mathrm{Mg} \mathrm{ha}^{-1}$ de calcário, realizado 30 dias antes do plantio, não influenciou o desempenho da cultura do milho (CASTRO et al., 2013b), como a dose máxima aplicada no presente trabalho foi $\left(2,94 \mathrm{Mg} \mathrm{ha}{ }^{-1}\right)$, e o tempo de reação curto, não houve reação para neutralizar os ácidos em quantidades suficiente para elevar o $\mathrm{V} \%$ a níveis que favorecem o desenvolvimento da planta a ponto de apresentar diferença nos tratamentos.

A resposta da cultura quanto a aplicação do calcário no início da safra, pode variar em função da regularidade das chuvas entre o período de aplicação do calcário e a semeadura, ou seja, mesmo que a aplicação do calcário seja feita 90 dias antes da semeadura, não significa que vai está reagindo durante todo este tempo, uma vez que as chuvas são irregulares no período inicial, podendo o solo ficar muitos dias sem conteúdo de água suficiente para ocorrer a reação.

O desenvolvimento do milho no primeiro ano de cultivo também não foi afetado pela forrageira (Tabela 1). Isso pode ser atribuído ao fato da forrageira ter sido semeada 25 dias após o milho, e pela maior taxa de crescimento do milho nos primeiros 30 dias, dando condições para sobressair à forrageira, esta que apresenta desenvolvimento inicial menor em comparação a cultura do milho (JAKELAITIS et al., 2006).

No segundo ano de cultivo (Tabela 2), observa-se que as variáveis: altura de planta (AP), altura de inserção de espiga (AIE), diâmetro do colmo (DC) e produtividade (PG), apresentaram interações significativas.

Tabela 2. Resumo da análise de variância para as variáveis altura de planta- AP (cm), altura de inserção de espiga -AIE $(\mathrm{cm})$, relação $\mathrm{AIE} / \mathrm{AP}$, diâmetro do colmo - DC $(\mathrm{mm})$, massa de mil grãos - M1000 (g) e produtividade - PG $\left(\mathrm{kg} \mathrm{ha}^{-1}\right)$ em área de segundo ano de cultivo de milho híbrido AG 1051 cultivado na safra 2011/2012 em Confresa-MT, Brasil.

\begin{tabular}{ccccccc}
\hline \multirow{2}{*}{ Fonte de variação } & \multicolumn{7}{c}{ Variável } \\
\cline { 2 - 7 } & AP & AIE & AIE/AP & DC & M1000 & PG \\
\hline Cultivo (C) & $18,780^{*}$ & $7,992^{* *}$ & $2,018^{\mathrm{NS}}$ & $3,903^{\mathrm{NS}}$ & $0,001^{\mathrm{NS}}$ & $0,143^{\mathrm{NS}}$ \\
\hline Saturação(S) & $3,772^{* *}$ & $1,245^{\mathrm{NS}}$ & $0,703^{\mathrm{NS}}$ & $1,954^{\mathrm{NS}}$ & $0,747^{\mathrm{NS}}$ & $3,835^{* *}$ \\
\hline C x S & $3,678^{*}$ & $8,634^{*}$ & $2,018^{\mathrm{NS}}$ & $3,270^{*}$ & $1,160^{\mathrm{NS}}$ & $3,313^{* *}$ \\
\hline Média & 144,07 & 69,13 & 0,48 & 13,82 & 248,18 & 3126,19 \\
C.V. (\%) & 2,73 & 3,83 & 3,88 & 6,19 & 10,38 & 9,20 \\
\hline
\end{tabular}

**, * e NS: significativo ( $p<0,05),(p<0,01)$ e não siginificativo, respectivamente, pelo teste F.

O desdobramento para os níveis de saturação por bases dentro dos sistemas de cultivo referente à $\mathrm{AP}, \mathrm{AIE}, \mathrm{DC}$ e PG no segundo ano de cultivo estão apresentados na Tabela 3.

Analisando os sistemas de cultivo dentro de cada nível de saturação por bases, verifica-se que quando o milho foi cultivado com saturação por bases 45 e $60 \%$, o sistema de monocultivo apresentou menor AP e AIE, sendo que o sistema de cultivo não influenciou nos demais níveis de saturação por bases. 
Tabela 3. Desdobramento de formas de cultivo dentro de cada saturação por base V\% para as variáveis alturas de planta-AP, inserção de espiga-AIE, produtividade-PG e diâmetro do colmo-DC.

\begin{tabular}{|c|c|c|c|c|c|c|c|c|}
\hline \multirow{3}{*}{$\begin{array}{c}\text { Saturação } \\
\text { por bases } \\
\text { (\%) }\end{array}$} & \multicolumn{8}{|c|}{ Cultivo } \\
\hline & \multicolumn{2}{|c|}{$\mathrm{AP}(\mathrm{cm})$} & \multicolumn{2}{|c|}{ AIE $(\mathrm{cm})$} & \multicolumn{2}{|c|}{$\mathrm{PG}\left(\mathrm{kg} \mathrm{ha}^{-1}\right)$} & \multicolumn{2}{|c|}{$\mathrm{DC}(\mathrm{mm})$} \\
\hline & $M+M$ & $M$ & $M+M$ & $M$ & $M+M$ & $M$ & $M+M$ & $M$ \\
\hline 25 & $139,70 \mathrm{a}$ & $142,06 \mathrm{a}$ & $66,31 a$ & $68,85 a$ & $2812,96 a$ & $3060,83 a$ & $14,06 a$ & $13,44 a$ \\
\hline 45 & $148,57 a$ & $140,27 \mathrm{~b}$ & $72,37 a$ & $67,35 \mathrm{~b}$ & $2990,92 a$ & $3396,85 a$ & $13,39 a$ & $13,63 a$ \\
\hline 60 & 153,75 a & $141,13 \mathrm{~b}$ & $74,10 a$ & $64,84 \mathrm{~b}$ & $3409,72 a$ & $3341,66 a$ & $15,50 a$ & $13,37 \mathrm{~b}$ \\
\hline 75 & 146,35 a & $140,76 \mathrm{a}$ & $69,02 \mathrm{a}$ & $70,18 \mathrm{a}$ & $3214,14 a$ & $2782,46 \mathrm{~b}$ & $13,52 \mathrm{a}$ & $13,65 \mathrm{a}$ \\
\hline Média & 147,09 & 141,05 & 70,45 & 67,80 & 3106,93 & 3145,45 & 14,12 & 13,52 \\
\hline
\end{tabular}

Médias seguidas por letras distintas na linha para cada variável, diferem estatisticamente entre si, pelo teste de Tukey a $5 \%$. M+M=Milho+Marandu; $M=$ Monocultivo.

O DC foi influenciado pela forma de cultivo, apenas na saturação por base $60 \%$, onde o cultivo em consórcio resultou em maior diâmetro (Tabela 3). Essa maior altura e maior DC em saturação por bases próximas a $60 \%$ estão relacionadas ao maior desenvolvimento da gramínea cultivada no ano anterior, pois a mesma apresenta maior desenvolvimento em saturação próxima a $60 \%$ (SOUSA; LOBATO, 2004), e consequentemente deixa maior resíduo no solo.

Quanto à produtividade, quando se elevou a saturação para $75 \%$ houve diferença para os sistemas de cultivo, sendo que o cultivo milho+Marandu resultou em maior produtividade, isso pode ser explicado pelo fato de ter ficado $10 \mathrm{Mg} \mathrm{ha}^{-1}$ de palhada do capim Marandu do ano anterior, conforme Brachtvogel et al. (2012) avaliando capim Marandu no mesmo experimento. Assim, a palhada manteve o solo em condições mais favoráveis para desenvolvimento de microrganismos de solo e também pela ciclagem de nutrientes (LOPES; NETO, 2011), pois no monocultivo o solo não tem palhada do capim. Para os demais níveis de V\%, a forma de cultivo não interferiu na produtividade. Como o capim Marandu não interferiu na produtividade do milho, torna-se viável o cultivo do milho+Marandu, Silva et al. (2015) avaliando densidade de capim Urochloa brizantha cv. Piatã em consórcio com milho não encontraram diferença na produtividade do milho quando cultivado com o capim Piatã até densidade de 15 plantas $\mathrm{m}^{-2}$. Como no cultivo de milho+Marandu a densidade do capim é reduzida buscando a menor interferência possível no milho, este sistema de cultivo milho+Marandu pode ser implantado como uma alternativa sem que haja interferência negativa no cultivo do milho (QUEIROZ et al., 2016).

Desdobrando os níveis de saturação por bases dentro das formas de cultivos para a variável altura de planta (Figura $2 \mathrm{~A}$ ), observa-se que no sistema monocultivo, os dados não se ajustaram aos modelos testados (linear e quadrático), já no sistema de cultivo em consórcio com capim Marandu, os dados se ajustaram ao modelo quadrático, sendo o ponto de máxima aproximadamente $152 \mathrm{~cm}$, com a saturação por base de aproximadamente $56 \%$.

O desdobramento da variável AIE para os níveis de saturação por bases quando no cultivo milho+Marandu (Figura 2B), segue a mesma tendência da AP, onde $O$ maior AIE foi aproximadamente $74 \mathrm{~cm}$, com a saturação por base de aproximadamente $53 \%$. As variáveis AP e AIE se comportaram de forma semelhante, onde apresentaram as maiores AP e AIE nos níveis de saturação por bases aproximados $56 \%$ e $53 \%$, respectivamente. No monocultivo os dados de AIE se ajustaram ao modelo de regressão quadrática com ponto de mínima, onde teve sua menor altura $(65 \mathrm{~cm})$, no nível de saturação por base próximo de $53 \%$.

No entanto, essa menor AIE no monocultivo não representa efeito negativo, pois o corte no momento da colheita pode ser feito mais baixo, pelo fato de não haver forrageira. Por outro lado, quando cultivado em consórcio com forrageiras a maior AIE é desejável, visto que a plataforma da colhedora irá trabalhar em alturas maiores e dessa forma terá menor massa de forrageira ceifada, resultando em menor tempo de vedação até o primeiro pastejo (CRUSCIOL et al., 2010). 
Figura 2. Altura de planta (2A), altura de inserção de espiga (2B) em função da saturação por bases em sistemas de monocultivo de milho (Solt) e milho+Marandu (Cons), safra 2011/2012 no município de Confresa - MT, Brasil.

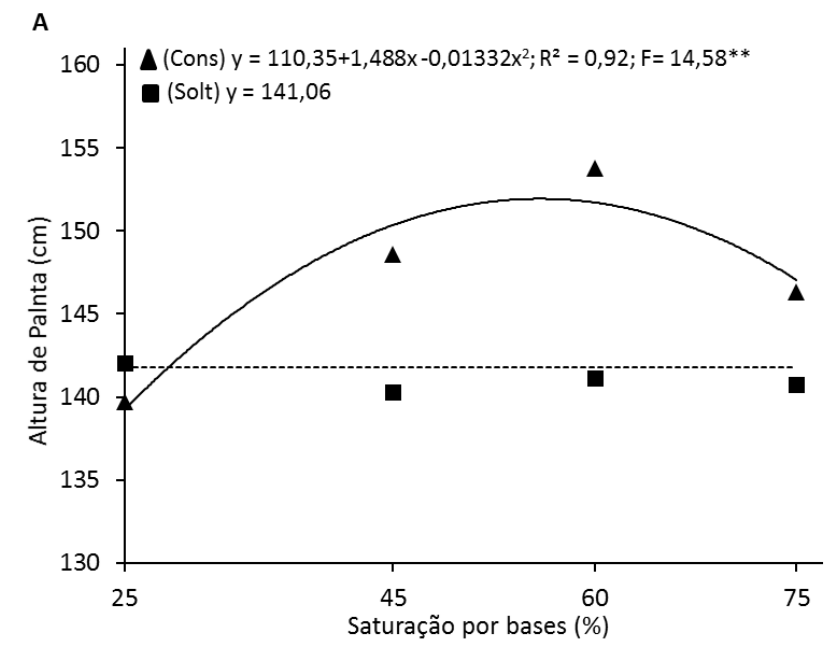

O desdobramento das formas de cultivos dentro de cada nível de saturação por bases apresentou diferença significativa no nível de saturação $60 \%$, com maior diâmetro de colmo quando o milho foi cultivado em consórcio (Tabela 3). Esse aumento mostra-se vantajoso, pois é uma das características morfológicas que mais tem sido relacionada com o percentual de acamamento ou quebramento de planta na cultura do milho (KAPPES et al., 2011). Já o desdobramento da variável diâmetro do colmo para os níveis de saturação por bases dentro das formas de cultivos não foi significativo para nenhum dos modelos testados (linear e quadrático), sendo a maior média obtida no cultivo milho+Marandu em saturação por bases 60\% (Tabela 3).

Para a produtividade do milho, tanto o cultivo milho+Marandu quanto o monocultivo se ajustaram ao modelo quadrático, para o monocultivo a máxima PG (3440 $\mathrm{kg} \mathrm{ha}^{-1}$ ), foi obtida com a saturação por base de $47 \%$ (Figura $3)$, valor próximo ao verificado por Figueiredo et al. (2012) e recomendado pelos autores para saturação por base para milho em solos altamente intemperizados. Já para modalidade de cultivo milho+Marandu, a máxima (3280 kg ha${ }^{1}$ ), foi alcançada quando a saturação por base foi de aproximadamente 65\%. Esses resultados reforçam o efeito positivo da calagem em doses adequadas para a região do Cerrado, que também está próxima da recomendação proposta por (SOUSA; LOBATO, 2004).

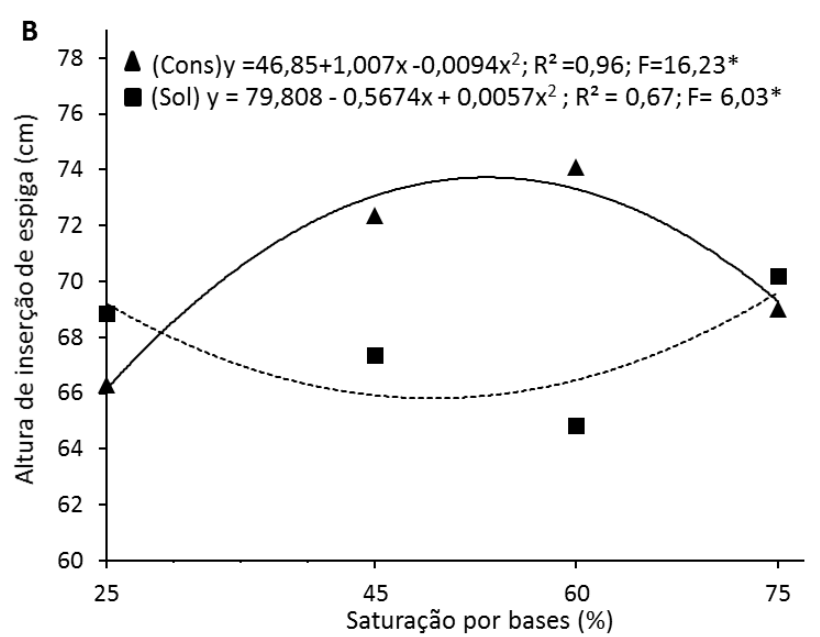

Pôde-se observar que no segundo ano após a correção do solo, houve efeito para o fator saturação, o que indica que o calcário aplicado no ano anterior teve seu efeito corretivo apenas no segundo ano. Já as formas de cultivo em geral não diferiram nessa pesquisa, dados estes que estão de acordo com alguns autores que também não encontraram diferença quando se cultivou milho em consórcio com capim (ALVES et al., 2013).

As produtividades de milho no presente estudo foram inferiores aos obtidos comumente na região, isto pode ter ocorrido devido a veranicos na região e também pelo fato da semeadura ter sido feita mais tarde, o que acelera o florescimento e consequentemente reduz a produtividade (SANS; SANTANA, 2002). Outro fato que contribui para essas produtividades baixas é o cultivo ser realizado em áreas após pastagens degradadas, visto que nessas áreas as produtividades tendem a serem menores em relação a áreas agrícolas já estabelecidas (ALVARENGA et al., 2008). Os dados de produtividade estão na mesma faixa dos obtidos em experimento conduzido na mesma classe de solo do presente estudo (VELOSO et al., 2016). Também avaliando cultivo de milho AG1051 em consórcio com U. Brizantha, Silva et al. (2011) obtiveram rendimentos médios de $3231 \mathrm{~kg} \mathrm{ha}^{-1}$, resultados próximos ao obtidos neste estudo. 
Figura 3. Produtividade em função da saturação por bases em sistemas de cultivo milho+Marandu (Con) e monocultivo (Sol), safra 2011/2012 no município de Confresa - MT, Brasil.

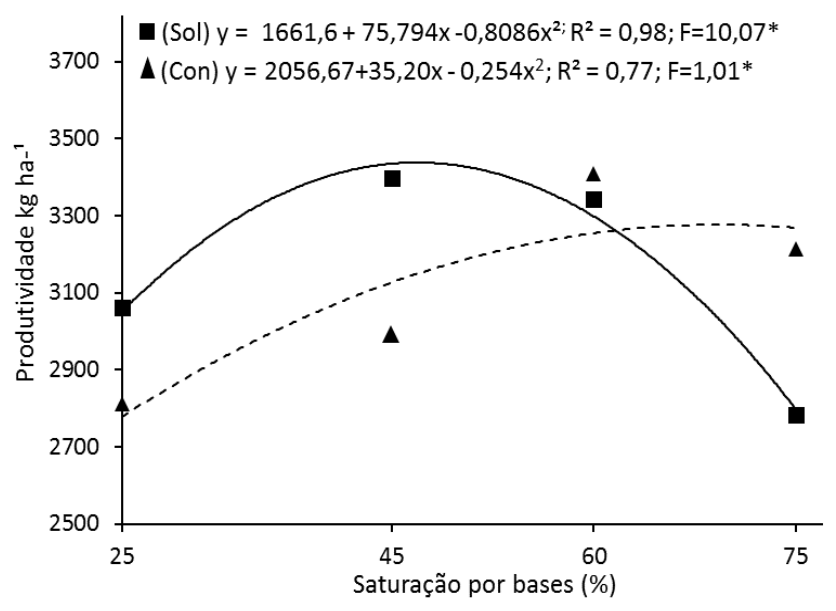

Mesmo não havendo diferença significativa (Tabela 3), é importante observar por meio da Figura 3, que a produtividade do milho no cultivo milho+Marandu é inferior até a saturação $60 \%$, a partir desse ponto a produtividade do monocultivo foi menor, pois teve uma queda acentuada de produtividade, isso pode ter ocorrido pelo fato da saturação por base acima de $50 \%$ em solos arenosos indisponibilizar os micronutrientes catiônicos (GONÇALVES et al., 2018). Já no cultivo milho+Marandu, o ponto de máxima produtividade em maior valor de saturação por bases, pode ser devido a competição com a forrageira, sendo que a produção do Urochloa brizantha $\mathrm{cv}$. Marandu foi de $10 \mathrm{Mg} \mathrm{ha}^{-1}$, ou seja, além da produtividade do milho, a forrageira também está absorvendo nutrientes, requerendo assim maior fertilidade do solo (GIMENES et al., 2008).

\section{Conclusões}

O milho não responde a aplicação de calcário realizada no mesmo ano de cultivo, respondendo apenas no segundo ano.

O cultivo de milho+Marandu não interfere na produtividade do milho, sendo as saturações por bases próximas à $50 \%$ no monocultivo e $65 \%$ no cultivo de milho+Marandu que resultam em maiores produtividades do milho.

O cultivo de milho+Marandu resulta em plantas maiores, com maiores alturas de inserções de espigas e maiores diâmetros de colmos.

\section{Referências}

ABIEC. Perfil da Pecuária no Brasil - Relatório Anual 2018. Disponível em: http://abiec.siteoficial.ws/images/upload/sumari o-pt-010217.pdf

ALVARENGA, R. C.; COBUCCI, T.; KLUTHCOUSKI, J.; WRUCK, F. J.; CRUZ, J. C.; GONTIJO NETO, M. M. A Cultura do Milho na integração Lavoura-Pecuária. In: CRUZ, J. C.; KARAM, D.; MONTEIRO, M. A. R.; MAGALHÃES, P. C. (Ed.). A Cultura do Milho. Embrapa Milho e Sorgo, 2008. p. 491-517.

ALVES, V. B.; CECCON, G.; LEITE, L. F. Morfologia e produtividade de híbridos de milho safrinha solteiro e consorciado com braquiária. Revista Brasileira de Milho e Sorgo, v. 12, n. 2, p. 152163, 2013. http://dx.doi.org/10.18512/19806477/rbms.v12n2p152-163

BRASIL. Ministério da Agricultura, Pecuária e Abastecimento. Regras para análise de sementes. Ministério da Agricultura, Pecuária e Abastecimento. Secretaria de Defesa Agropecuária. Brasília: MAPA/ACS, 2009. 395p.

BRACHTVOGEL, E. L.; BRITO, A. R.; CABRAL, A. S.; SOUSA, A. D. R.; PEREIRA, H. S. CRUZ, S. C. S. Desempenho de Brachiaria brizantha cV. Marandu em Diferentes Níveis de Saturação por Bases no Sistema de Integração Lavoura-Pecuária "Santa Fé". In: FERTIBIO, 2012, Maceió. Anais [...]. 2012.

CALONEGO, J.; MORA, V.; SANTOS, C.; OLIVEIRA, L. Calagem e silicatagem em solo incubado com 
diferentes umidades. Colloquium Agrariae, v.8, n.2, p.46-56, 2012. https://doi.org/10.5747/ca.2012.v08.n2.a078

CARVALHO, W. T. V.; MINIGHIN, D. C.; GONÇALVES, L. C.; VILLANOVA, D. F. Q.; MAURICIO, R. M.; PEREIRA, R. V. G. Pastagens degradadas e técnicas de recuperação: Revisão. Pubvetv, v.11, n.10, p.1036-1045, 2017. http://dx.doi.org/10.22256/pubvet.v11n10.1036$\underline{1045}$

CASTRO, A. M. C.; ALMEIDA, Y. F. R.; ARLANCH, A. B.; BAPTISTA, J. P. Tempo de reação de calcário e gesso no desenvolvimento da planta de milho. Cultivando o saber, v.6, n.3, p.10-25, 2013 a.

CASTRO, A. M. C.; RUPPENTHAL, V; RANDO, E. M.; MARCHIONE, M. S.; GOMES, C. J. A. Calcário e gesso no desenvolvimento do milho cultivado em um Latossolo Vermelho Amarelo distrófico. Cultivando o Saber, v.6, n.1, p.8-16, 2013b.

CRUSCIOL, C. A. C.; SORATTO, R. P.; BORGHI, E.; MATEUS, G. Benefits of integrating crops and tropical pastures as systems of production. Better Crops International, v. 94, n. 2, p. 14-16, 2010.

CRUSCIOL, C. A. C.; MATEUS, G. P.; PARIZ, C. M. BORGHI, E.; COSTA, C.; SILVEIRA, J. P. F. Nutrição e produtividade de híbridos de sorgo granífero de ciclos contrastantes consorciados com capimmarandu. Pesquisa agropecuária brasileira, v.46, n.10, p.1234-1240, 2011. http://dx.doi.org/10.1590/S0100204X2011001000017

DIAS-FILHO, M. B. Degradação de pastagens: o que é e como evitar. Brasília: Embrapa, 2017. 19p. Disponível em: https://www.infoteca.cnptia.embrapa.br/infotec a/bitstream/doc/1070416/1/TC1117CartilhaPasta gemv04.pdf

DIAS-FILHO, M. B. Diagnóstico das pastagens no Brasil. Belém, PA: Embrapa Amazônia Oriental, 2014. 36 p. (Documentos, 402). Disponível em: https://www.infoteca.cnptia.embrapa.br/bitstrea m/doc/986147/1/DOC402.pdf.

DUARTE, A. P.; KURIHARA, C. H.; CANTARELLA, H. Adubação do Milho Safrinha em Consórcio com Braquiária. In: CECCON, G. Consórcio MilhoBraquiária. Brasília: Embrapa, 2013. p. 113-141.
EMBRAPA. Centro Nacional de Pesquisa de Solos. Sistema brasileiro de classificação de solos. 3 . ed. Embrapa Solos. Rio de Janeiro, 2013. 353 p.

FAGERIA, N. K. Efeito da calagem na produção de arroz, feijão, milho e soja em solo de Cerrado. Pesquisa Agropecuária Brasileira, v. 36, n. 11, p. 1419-1424, 2001. http://dx.doi.org/10.1590/S0100$\underline{204 \times 2001001100013}$

FERREIRA, D. F. Sisvar: a computer statistical analysis system. Ciência e agrotecnologia, v. 35, n.6, p.1039-1042, 2011. http://dx.doi.org/10.1590/S141370542011000600001

FIGUEIREDO, C.C.; BARBOSA, D. V.; OLIVEIRA, S. A.; FAGIOLI, M.; SATO, J. H. Adubo fosfatado revestido com polímero e calagem na produção e parâmetros morfológicos de milho. Revista Ciência Agronômica, v. 43, n. 3, p. 446-452, 2012. http://dx.doi.org/10.1590/S1806$\underline{66902012000300005}$

FONSECA, I. C.; CECCON, G.; ALVES, V. B.; PADILHA, N. S.; LEITE, L. F. Produtividade de milho safrinha, solteiro e consorciado com Brachiaria ruziziensis em Dourados, MS. In: SEMINÁRIO NACIONAL DE MILHO SAFRINHA, 9., 2011, Lucas do Rio Verde. Anais [...]. Fundação Rio Verde: ABMS, 2011. P. 211-218. Disponível em:

http://ainfo.cnptia.embrapa.br/digital/bitstream/ item/50256/1/211-Produtividade.pdf

GIMENES, M. J.; VICTORIA FILHO, R.; PRADO, E. P.; POGETTO, M. H. F. A.; CHRISTOVAM, R. S. Interferência de espécies forrageiras em consórcio com a cultura do milho. Revista da FZVA, v.15, n.2, p. 61-76, 2008.

GONÇALVES, F. A. R.; XAVIER, F. O.; SILVA, R. R.; AQUINO, L. A.; CARVALHO, A. M. X.; NOVAIS, R. F. Influência da saturação por bases do solo sobre a disponibilidade e absorção de zinco. Cultura Agronômica, v.27, n.2, p.262-272, 2018.

GONTIJO NETO, M. M.; BORGHI, E.; RESENDE, A. V.; ALVARENGA, R. C. Benefícios e desafios da integração lavoura-pecuária na melhoria da qualidade dos solos do Cerrado. Informações Agronômicas, Piracicaba, n. 161, p. 9-21, 2018. Disponível em: 
http://www.ipni.net/publication/ia-

brasil.nsf/issue/ia-brasil-2018-161

IBGE. Censo agropecuário. 2017. Rio de Janeiro, 2017. p.1-108. Disponível em: https://biblioteca.ibge.gov.br/visualizacao/period icos/3093/agro 2017 resultados preliminares.p df

JAKELAITIS, A.; SILVA, A. A.; SILVA, A. F.; SILVA, L. L.; FERREIRA, L. R.; VIVIAN, R. Efeitos de herbicidas no controle de plantas daninhas, crescimento e produção de milho e Brachiaria brizantha em consórcio. Pesquisa Agropecuária Tropical, v. 36, n. 1, p. 53-60, 2006.

KAPPES, C.; ANDRADE, J. A. C.; ARF, O.; OLIVEIRA, A. C.; ARF, M. V.; FERREIRA, J. P. Desempenho de híbridos de milho em diferentes arranjos espaciais de plantas. Bragantia, v.70, n.2, p.334343, 2011. http://dx.doi.org/10.1590/s000687052011000200012

LOPES, H. R.; NETO, O. G. Benefícios da adoção da integração lavoura-pecuária. Cadernos de PósGraduação da FAZU, v.2, 2011. Disponível em: http://www.fazu.br/ojs/index.php/posfazu/articl e/viewFile/434/326

MACEDO, M. C. M. M. Integração lavoura e pecuária: o estado da arte e inovações tecnológicas. Revista Brasileira de Zootecnia, Viçosa, v.38, Supl. Esp., p.133-146, 2009. http://dx.doi.org/10.1590/S1516-

$\underline{35982009001300015}$

QUEIROZ, R. F.; CHIODEROLI, C. A.; FURLANI, C. E. A.; HOLANDA, H. V.; ZERBATO, C. Maize intercropped with Urochloa ruziziensis under notillage system. Pesquisa Agropecuária Tropical, v.46, n.3, p.238-244, 2016. http://dx.doi.org/10.1590/1983-

40632016v4640464

RAIJ, B. V.; ANDRADE, J. C.; CANTARELLA, M.; QUAGGIO, J. A. Análise química para avaliação da fertilidade de solos tropicais. Campinas: Instituto Agronômico de Campinas, 2001. 285 p.

RAIJ, B. V.; CANTARELLA, H.; QUAGGIO, J.A.; FURLANI, A.M.C. (Ed.) Recomendações de adubação e calagem para o Estado de São Paulo. 2. ed. Campinas: IAC, 1997. 285p. (Boletim Técnico, 100).
SANS, L.M.A.; SANTANA, D.P. Cultivo do milho: clima e solo. Embrapa Milho e Sorgo. 2002. Comunicado técnico, 38. Disponível em: http://www.infoteca.cnptia.embrapa.br/infoteca handle/doc/486999

SILVA, D. V.; PEREIRA, G. A. M; FREITAS, M. A. M.; SILVA, A. A.; SEDIYAMA, T.; SILVA, G. S.; FERREIRA, L. R.; CECON, P. R. Produtividade e teor de nutrientes do milho em consórcio com braquiária. Ciência Rural, v.45, n.8, p.1394-1400, $2015 . \quad$ http://dx.doi.org/10.1590/0103$\underline{8478 \mathrm{cr} 20140760}$

SILVA, M. G. O.; FREITAS, F. C. L.; MESQUITA, H. C.; NASCIMENTO, P. G. M. L. RODRIGUES, A. P. M. S.; SANTANA, F. A. O. Rendimento de grãos de cultivares de milho em consórcio com Brachiaria brizantha. Agropecuária Científica no Semiárido, v.7, n.1, p.23-29, 2011.

SILVA, R. O.; BARIONI, L. G.; HALL, J. A. J.; MORETTI, A. C.; VELOSO, R. F.; ALEXANDER, P. CRESPOLINI, M.; MORAN, D. Sustainable intensification of Brazilian livestock production through optimized pasture restoration. Agricultural Systems, v.153, p.201-211, 2017. https://doi.org/10.1016/j.agsy.2017.02.001

SOUSA, D. M. G.; LOBATO, E. Cerrado: Correção do Solo e Adubação. 2. ed. Embrapa Informação Tecnológica, 2004. 416 p.

SOUSA, D. M. G.; MIRANDA, L. N.; OLIVEIRA, S. A. Acidez do solo e sua correção. In: NOVAIS, R. F.; ALVAREZ V., V. H.; BARROS, N. F.; FONTES, R. L. F.; CANTARUTTI, R. B.; NEVES, J. C. L. Fertilidade do solo. Viçosa, MG: Sociedade Brasileira de Ciência do Solo, 2007. p. 205-274.

TROGELLO, E.; MODOLO, A. J.; CARNIELETTO, R.; KOLLING, E. M.; SCARSI, M.; SGARBOSSA, M. Desenvolvimento inicial e produtividade da cultura do milho no sistema de integração lavoura-pecuária. Revista Ceres, v.59, n.2, p.286291, 2012. http://dx.doi.org/10.1590/S0034$\underline{737 \times 2012000200019}$

TSUJIGUSHI, B. P.; KURIHARA, C. H.; CARVALHO, L. A. Calagem, gessagem e manejo da adubação em milho safrinha consorciado com Brachiaria ruziziensis. In: Seminário nacional de milho 
safrinha, 12., 2013, Dourados. Anais [...]. Brasília, DF: Embrapa, 2013. 1 Cd-rom.

VELOSO, C. A. V.; SILVA, A. R.; CARVALHO, E. J. M.; SLVEIRA FILHO, A. Produção de grãos de milho sob manejo da adubação fosfatada em latossolo amarelo distrófico no Oeste Paraense.

Belém, PA: Embrapa Amazônia Oriental, 2016. 